Original Article

\title{
Knowledge and attitude of South-Indian smokers towards smoking associated health risk
}

\section{Ananya Madiyal ${ }^{1}$, Vidya Ajila ${ }^{2}$, G. Subhas Babu', Shruthi Hegde ${ }^{4}$}

${ }^{1}$ Lecturer, ${ }^{2,4}$ Reader, ${ }^{3}$ Professor and Head of the department, Department of Oral Medicine and Radiology, A. B. Shetty Memorial Institute of Dental Sciences, Nitte University.

*Corresponding Author : Ananya Madiyal, Lecturer, Department of Oral M edicine and Radiology, A. B. Shetty M emorial Institute of Dental Sciences, Nitte University

$\begin{array}{ll}\text { Received } & : 23.03 .2017 \\ \text { Review Completed } & : 06.05 .2017 \\ \text { Accepted } & : 07.05 .2017\end{array}$

Keywords : Smoking, Cessation, Tobacco

\begin{tabular}{|c|}
\hline Access this article online \\
\hline Quick Response Code \\
\hline
\end{tabular}

\begin{abstract}
Aim: To assess the knowledge and attitude of South-Indian smokers towards health effects of smoking and their intentions to quit.

Study design: A cross sectional questionnaire based survey was conducted among 550 smokers hailing from South India who reported to the out-patient department of the dental hospital.

Results: Highest incidence of smoking in men was seen in those who received moderate level of education and those residing in rural areas. In female smokers, the highest incidence was seen in those residing in urban areas (53.8\%) with a high level of education (38.4\%). We found that males continued their habit mainly to destress while females used it to socialize. Majority of the participants were aware that smoking causes a host of problems in the oral cavity and $68.18 \%$ were aware that passive smoking was injurious to the body. M ost of the responders admitted to having observed warnings on tobacco products and were willing to quit the habit with help from their dentists.
\end{abstract}

Conclusion: Smokers are at risk for various diseases that include the cardiovascular, respiratory and reproductive systems as well as the oral cavity. This study sheds light on the level of awareness among current tobacco users and the areas of deficiency in patient education which should be addressed by clinicians.

\section{Introduction}

Tobacco is considered to be one of the major risk factors for oral cancer, oral cancer recurrence, dental caries, periodontal diseases and cleft lip and palate. Tobacco use is primarily due to nicotine, a tobacco alkaloid that contains a cyclic nitrogenous nucleus. This component of tobacco exerts a psychopharmacological effect which causes a need for repeated use. ${ }^{1}$ Cigarette smokers have two to three times greater risk of developing oral cancer when compared to non-smokers.Although the risk decreases after abstinence, it takes several years for it to reach the levels seen in non-smokers. ${ }^{2}$ In the Indian peninsula, tobacco smoking causes $50 \%$ of all of the cancers in males and $25 \%$ of all of the cancers in the female population. ${ }^{3}$

For over four centuries, smoking has been seen to be one of the most compelling addictions prevailing in the society. It affects numerous organs in the body and causes a number of tobacco-related diseases, with the respiratory tract and cardiovascular system being the most commonly affected. Many of its effects occur due to secondary consequences of continuous exposure to the chemical constituents of tobacco smoke. This causes various inflammatory reactions which affect the immune system. In addition to this, smokers are predisposed to respiratory diseases as a consequence of allergy and have an increased vulnerability to infections. ${ }^{4}$ Burning of cigarettes produces nearly six thousand by-products which include metals, tobacco glycol proteins and polycyclic aromatic hydrocarbons, many of which are known to be mutagenic, carcinogenic or antigenic. $^{5}$

As the heated air caused by burning tobacco is inhaled, it passes through the unburned tobacco dissolving its constituents on the way. When this heated air cools, the dissolved components condense to form smoke particles 
which are then inhaled. The aerosol thus produced contains particles in the micron range which permits effective penetration in the lungs and rapid absorption into systemic blood. ${ }^{5}$ Oral cavity is the first to come across the various chemicals that are present in tobacco smoke. High concentrations of noxious compounds in cigarette smoke explain the prevalence of caries, periodontal disease and malignancies in the oral cavity of smokers. Cigarette smoke contains powerful oxidants like volatile aldehydes and oxygen free radicals which can cause serious damage to enzymes and proteins which leads to a host of physiologic problems. ${ }^{6}$ The present questionnaire survey was undertaken with the intention to gain information on the knowledge and attitude of smokers towards tobacco associated health risk as well as to assess their intentions to quit.

\section{Materials and Methods}

A cross-sectional survey was conducted among 550 smokers who reported to the out-patient department of the dental hospital. The target population included adult smokers from South-India who were over 18 years of age and who admitted to smoking at least one tobacco product per day since the last one year. Informed consent was obtained from the participants of the survey. Data was collected through face-to-face interview technique.

Demographic data such as age, sex, education and area of residence were included in the analysis. Age was divided into four categories as <20 years, 21-40 years, 41-60 years and $>60$ years. The participant's highest level of education was recorded and categorized into low (illiterate or primary), moderate (middle or secondary) and high (graduate and post-graduate) according to Sansone et al. ${ }^{7}$ Area of residence was categorised into rural, semiurban and urban based on the address provided by the responders.

All participants were asked a series of questions regarding their knowledge and attitude towards smoking of various tobacco products; specifically if smoking caused the following health outcomes: stained teeth, tooth decay, bad breath, change in taste, gum problems, cardiac diseases, reproductive problems and cancers of the lung and oral cavity. Their reason for continuing the habit was assessed and categorized into: socialising, increasing focus or to relax or destress. They were also assessed on their knowledge of the addictive properties of tobacco, adverse effects of passive smoking and the ill-effects of smoking during pregnancy. Participants were asked if they were aware of the ban on smoking in public places and if they have noticed the warning labels and pictures on the packaging around tobacco products. Their willingness towards quitting the habit was assessed by asking if they would expect their dentist to provide information regarding the effects of tobacco and if they expected the dentist's help during the period of quitting. All responses were coded as 'yes', 'no' and 'can't comment'.

\section{Results}

The socio-demographic details of the participants showed that the highest percentage of male smokers was in the 4160 years age group (50.1\%) while in females the highest incidence was in the 21-40 years age group (69.2\%) (Table 1 , Figure 1). Highest incidence of smoking in men was seen in those who received moderate level of education (36.4\%) while in women it was seen in those who received high level of education (38.4\%) (Table 1, Figure 1). Males residing in rural areas were found to have the highest incidence of smoking (51.7\%) while women in urban areas showed the highest incidence (53.8\%) (Table 1, Figure 1). $53.8 \%$ of males smoked 5-10 tobacco products per day while $80.7 \%$ of women smoked less than 5 tobacco products per day (Table 1, Figure 1).

Highest number of male smokers (52.2\%) admitted to continuing their smoking habit to relax or destress while women $(80.7 \%)$ said they mainly smoked in order to socialise (Table 2, Figure 2). Majority of smokers agreed that smoking caused bad breath (86.5\%), change in taste $(71.4 \%)$ and stains on the teeth (72\%). However a bulk of the study population did not believe that the habit would lead to tooth decay (55.8\%) (Table 3, Figure 3). M ales were aware of health problems such as gum disease (52.8\%), heart disease (69.4\%), lung cancer (93.1\%) and oral cancer 
(65.07\%). Female respondents were aware of smoking leading to heart disease (65.3\%), lung cancer (100\%) and oral cancer (73.07\%). However the responders were not aware of the effect of smoking on reproductive health (76.3\%) (Table 4, Figure 4). All participants were aware that smoking was addictive and a majority believed that smoking during pregnancy can have adverse effects on the baby (72\%) and that passive smoking was also injurious to the body (68.18\%) (Table.5)

All female smokers and $92.7 \%$ of males were aware of the ban on smoking in public places and all admitted to having observed the warning labels on these products (Table 6). Majority of the participants were in agreement that the dentist should be able to explain (71.45\%), help and guide them towards quitting $(82.18 \%)$ and that they believed that they could quit with the help of a dentist (75.09\%) (Table 7, Figure 5).

Figure 1: Graph showing socio-demographic details of the study population.

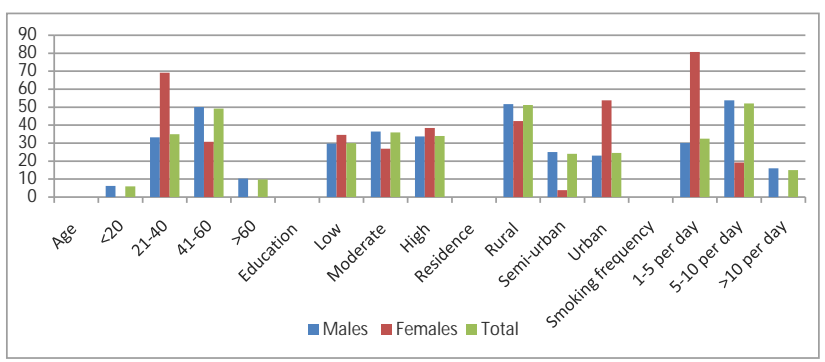

Table 1 : showing socio-demographic details of participants.

\begin{tabular}{|l|c|c|c|}
\hline & Males (\%) & Females (\%) & Total (\%) \\
\hline Age & & & \\
\hline$<20$ & 6.2 & 0 & 6 \\
\hline $21-40$ & 33.2 & 69.2 & 34.9 \\
\hline $41-60$ & 50.1 & 30.7 & 49.2 \\
\hline$>60$ & 10.3 & 0 & 9.8 \\
\hline Education & & & \\
\hline Low & 29.7 & 34.6 & 30 \\
\hline M oderate & 36.4 & 26.9 & 36 \\
\hline High & 33.7 & 38.4 & 34 \\
\hline Residence & & & \\
\hline Rural & 51.7 & 42.3 & 51.2 \\
\hline Semi-urban & 25.1 & 3.8 & 24.1 \\
\hline Urban & 23 & 53.8 & 24.5 \\
\hline Smoking frequency & & & \\
\hline 1-5 per day & 30.1 & 80.7 & 32.5 \\
\hline 5-10 per day & 53.8 & 19.2 & 52.1 \\
\hline$>10$ per day & 16 & 0 & 15 \\
\hline
\end{tabular}

Figure 2 : Graph showing reasons for continuation of the habit.

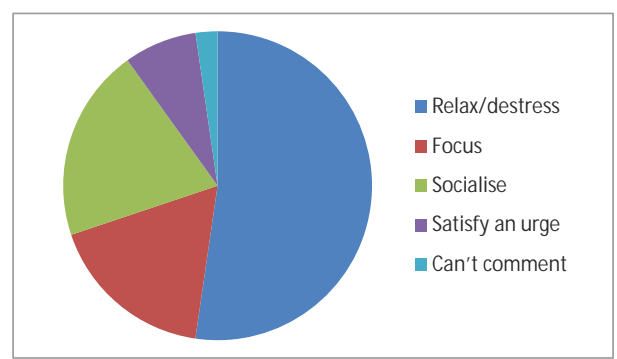

Table 2 : showing reason for continuing the habit

\begin{tabular}{|l|c|c|c|c|c|}
\hline & Relax/distress (\%) & Focus (\%) & Socialise (\%) & Satisfy an urge (\%) & Can't comment (\%) \\
\hline M ales & 52.29 & 17.55 & 20.22 & 7.63 & 2.29 \\
\hline Females & 19.23 & 0 & 80.76 & 0 & 0 \\
\hline Total & 50.72 & 16.72 & 23.09 & 7.27 & 2.18 \\
\hline
\end{tabular}

Table 3 : Showing knowledge of smokers towards health effects.

\begin{tabular}{|c|c|c|c|c|c|c|c|c|c|c|c|c|}
\hline & \multicolumn{3}{|c|}{ Bad breadth } & \multicolumn{3}{|c|}{ stains } & \multicolumn{3}{|c|}{ decay } & \multicolumn{3}{|c|}{ Change in taste } \\
\hline & $\begin{array}{c}\text { Males } \\
(\%)\end{array}$ & $\begin{array}{c}\text { Females } \\
(\%)\end{array}$ & $\begin{array}{c}\text { Total } \\
(\%)\end{array}$ & $\begin{array}{c}\text { Males } \\
(\%)\end{array}$ & $\begin{array}{c}\text { Females } \\
(\%)\end{array}$ & $\begin{array}{c}\text { Total } \\
(\%)\end{array}$ & $\begin{array}{c}\text { Males } \\
(\%)\end{array}$ & $\begin{array}{c}\text { Females } \\
(\%)\end{array}$ & $\begin{array}{c}\text { Total } \\
(\%)\end{array}$ & $\begin{array}{c}\text { Males } \\
(\%)\end{array}$ & $\begin{array}{c}\text { Females } \\
(\%)\end{array}$ & $\begin{array}{c}\text { Total } \\
(\%)\end{array}$ \\
\hline Yes & 87.21 & 73.07 & 86.54 & 71.54 & 80.76 & 72 & 15.45 & 0 & 14.72 & 70.41 & 92.30 & 71.45 \\
\hline No & 8.39 & 0 & 8 & 18.7 & 11.53 & 18.36 & 55.15 & 69.23 & 55.81 & 29.58 & 7.69 & 28.54 \\
\hline $\begin{array}{l}\text { Can't } \\
\text { comment }\end{array}$ & 4.3 & 26.92 & 5.45 & 9.73 & 7.69 & 9.63 & 29.38 & 30.76 & 29.45 & 0 & 0 & 0 \\
\hline
\end{tabular}


Figure 3 : Graph showing awareness regarding various health effects of smoking

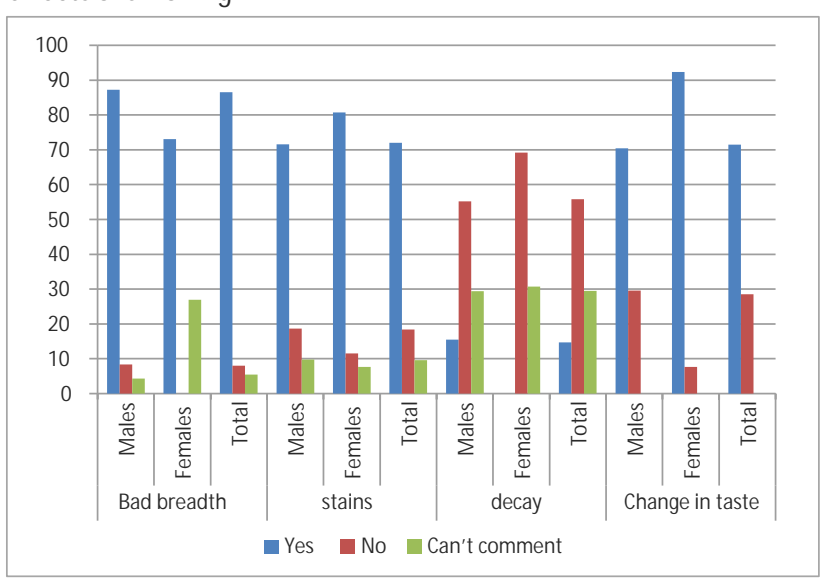

Figure 4 : Graph showing knowledge of smokers regarding illeffects of smoking.

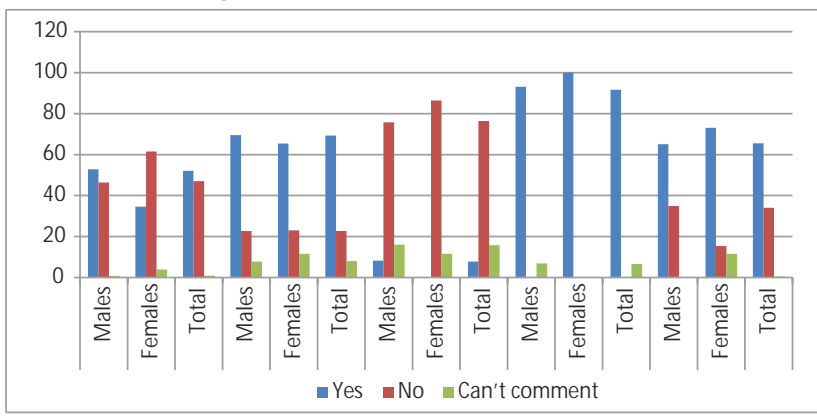

Table 4 : Showing knowledge of smokers regarding health problems caused by smoking.

\begin{tabular}{|l|c|c|c|c|c|c|c|c|c|c|c|c|c|c|c|}
\hline & \multicolumn{3}{|c|}{ Gum disease } & \multicolumn{3}{|c|}{ Heart disease } & \multicolumn{3}{|c|}{ Reproductive problems } & \multicolumn{3}{c|}{ Lung cancer } & \multicolumn{3}{c|}{ Oral cancer } \\
\hline & $\begin{array}{c}\text { Males } \\
(\%)\end{array}$ & $\begin{array}{c}\text { Females } \\
(\%)\end{array}$ & $\begin{array}{c}\text { Total } \\
(\%)\end{array}$ & $\begin{array}{c}\text { Males } \\
(\%)\end{array}$ & $\begin{array}{c}\text { Females } \\
(\%)\end{array}$ & $\begin{array}{c}\text { Total } \\
(\%)\end{array}$ & $\begin{array}{c}\text { Males } \\
(\%)\end{array}$ & $\begin{array}{c}\text { Females } \\
(\%)\end{array}$ & $\begin{array}{c}\text { Total } \\
(\%)\end{array}$ & $\begin{array}{c}\text { Males } \\
(\%)\end{array}$ & $\begin{array}{c}\text { Females } \\
(\%)\end{array}$ & $\begin{array}{c}\text { Total } \\
(\%)\end{array}$ & $\begin{array}{c}\text { Males } \\
(\%)\end{array}$ & $\begin{array}{c}\text { Females } \\
(\%)\end{array}$ & $\begin{array}{c}\text { Total } \\
(\%)\end{array}$ \\
\hline Yes & 52.86 & 34.61 & 52 & 69.46 & 65.38 & 69.27 & 8.2 & 0 & 7.81 & 93.12 & 100 & 91.63 & 65.07 & 73.07 & 65.45 \\
\hline No & 46.37 & 61.53 & 47.09 & 22.70 & 23.07 & 22.72 & 75.76 & 86.46 & 76.36 & 0 & 0 & 0 & 34.92 & 15.38 & 34 \\
\hline $\begin{array}{l}\text { Can't } \\
\text { comment }\end{array}$ & 0.76 & 3.84 & 0.9 & 7.82 & 11.53 & 8 & 16.03 & 11.53 & 15.81 & 6.87 & 0 & 6.54 & 0 & 11.53 & 0.54 \\
\hline
\end{tabular}

Table 5 : Showing awareness of ill-effects of smoking.

\begin{tabular}{|l|c|c|c|c|c|c|c|c|c|}
\hline & \multicolumn{3}{|c|}{ Addictive property of tobacco } & \multicolumn{3}{c|}{ Tobacco is harmful during pregnancy } & \multicolumn{3}{c|}{ Passive smoking is injurious } \\
\hline & Males (\%) & Females (\%) & Total (\%) & Males (\%) & Females (\%) & Total (\%) & Males (\%) & Females (\%) & Total (\%) \\
\hline Yes & 100 & 100 & 100 & 71.94 & 73.07 & 72 & 47.17 & 86.46 & 68.18 \\
\hline No & 0 & 0 & 0 & 3.05 & 0 & 2.9 & 17.74 & 0 & 16.9 \\
\hline $\begin{array}{l}\text { Can't } \\
\text { comment }\end{array}$ & 0 & 0 & 0 & 25 & 26.92 & 25.09 & 15.07 & 11.53 & 14.9 \\
\hline
\end{tabular}

Table 6 : Showing awareness of ban and warning on tobacco products.

\begin{tabular}{|l|c|c|c|c|c|c|}
\hline & \multicolumn{4}{|c|}{ Aware about ban of smoking in public places } & \multicolumn{3}{c|}{ Noticed warning labels on tobacco products } \\
\hline & Males (\%) & Females (\%) & Total (\%) & Males (\%) & Females (\%) & Total (\%) \\
\hline Yes & 92.74 & 100 & 93.09 & 100 & 100 & 100 \\
\hline No & 7.25 & 0 & 6.9 & 0 & 0 & 0 \\
\hline Can't comment & 0 & 0 & 0 & 0 & 0 & 0 \\
\hline
\end{tabular}

Figure 5: Graph showing attitude of smokers towards quitting with dentist'shelp.

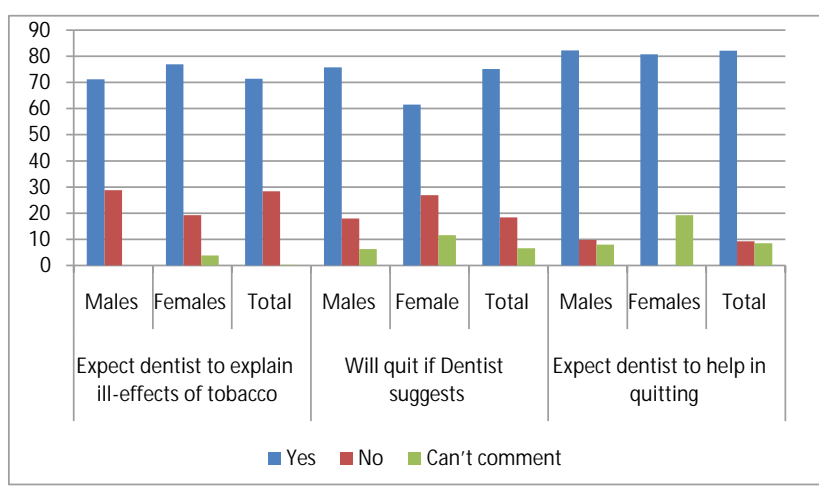

\section{Discussion}

Evidence of the daunting mortality concerns of smoking is well known. Smoking is an essential risk factor for a variety of pathologies. Pro-inflammatory effects of tobacco smoke include increased free radical burden, elevated neutrophil count and elevated circulatory T cells and CD4 activity. Tobacco smoke is also seen to be associated with immunosuppressive actions such as reduced interferon response, reduced antigen presenting activity, reduced circulating immunoglobulins, reduced $\mathrm{T}$ cell activity, reduced neutrophil activity and inhibition of inflammatory 
Table 7 : Showing attitude of smokers towards the role of dentist in quitting of the habit

\begin{tabular}{|c|c|c|c|c|c|c|c|c|c|}
\hline & \multicolumn{3}{|c|}{$\begin{array}{l}\text { Expect dentist to explain } \\
\text { ill-effects of tobacco }\end{array}$} & \multicolumn{3}{|c|}{ Will quit if Dentist suggests } & \multicolumn{3}{|c|}{ Expect dentist to help in quitting } \\
\hline & Males (\%) & Females (\%) & Total (\%) & Males (\%) & Females (\%) & Total (\%) & Males (\%) & Females (\%) & Total (\%) \\
\hline Yes & 71.18 & 76.92 & 71.45 & 75.76 & 61.53 & 75.09 & 82.25 & 80.76 & 82.18 \\
\hline No & 28.81 & 19.23 & 28.36 & 17.93 & 26.92 & 18.36 & 9.73 & 0 & 9.27 \\
\hline $\begin{array}{l}\text { Can't } \\
\text { comment }\end{array}$ & 0 & 3.84 & 0.18 & 6.29 & 11.53 & 6.54 & 8.01 & 19.23 & 8.54 \\
\hline
\end{tabular}

cytokines. ${ }^{5}$ Rani et al found that the incidence of smoking was higher in the poorer, rural and uneducated masses in both men and women in comparison with wealthier, urban and better educated population. These socioeconomic gradients were found to be steeper for females when compared to males. Higher probability of tobacco products was seen in the older population (>25 years) when compared with the younger population (15-24 years). ${ }^{8}$ In the present study we found that the incidence was higher in men of 41-60 year age group while women in the 21-40 year age group had a higher incidence. $M$ en residing in the rural areas and with moderate level of education were found to have a higher incidence while for women it was those in an urban setting with high level of education.

Formidable evidence suggests that development of asthma and an increase in the severity of its symptoms are due to active smoking among adolescents and adults. Strachan et al found a dose response relationship between exposure to tobacco and development of asthma. ${ }^{9}$ the tars produced by tobacco combustion contain irritants like acroline and formaldehyde which are responsible for chronic bronchitis and emphysema. Smoking is a known cause of chronic obstructive pulmonary disease (COPD) and it was seen that $80 \%$ of the deaths of people below the age of 40 is related to smoking. ${ }^{10}$ There exists a doseresponse relationship between smoking and cancer of the lung. The mortality rate of lung cancer is $23 \%$ more for males and $13 \%$ more for females who smoke more than 20 cigarettes per day in comparison with non-smokers. The risk for light smokers although lower, is still substantial. ${ }^{11}$ In the present study we found that all female smokers and $93 \%$ of male smokers were aware that smoking could cause cancer of the lung.
Smoking is one of the key risk factors for atherosclerosis. The mechanism of smoking induced damage to the endothelium is not yet recognized but it can be attributed to the fact that smoking increases interactions between the platelet and vessel wall or the inverse relationship between smoking and high density cholesterol in the plasma. ${ }^{11}$ Smoking causes a host of cardiovascular diseases ranging from peripheral vascular diseases to coronary heart disease and stroke. The risk of heart attack increases by a factor of two in a smoker when compared to a nonsmoker and it takes a period of 6 months of abstinence from smoking for the risk to equal that of a nonsmoker. ${ }^{12}$ We found that only $69.2 \%$ of the smokers were aware of the adverse effects of smoking on the heart. M any epidemiologic studies have documented the effects of passive smoking in the development of coronary heart disease. Evidence suggests that passive smoking contributes to atherosclerosis by sensitizing and activating the neutrophils and causing tissue damage through oxidant mediated reactions. ${ }^{13} \mathrm{We}$ found that $68.1 \%$ of the respondents were aware of the ill-effects of passive smoking on general health.

Sham et al identified various lesions in the oral cavity associated with tobacco use such as smokeless tobacco keratosis, erythroplakia, leukoplakia, oral cancer, halitosis, root caries, taste derangement, periodontal diseases, staining of teeth and restorations and peri-implantitis which they attributed to the carcinogens emitted from burning tobacco. It is also thought to arise from $\mathrm{pH}$ change, increased intra-oral temperature, alteration of immune response or altered resistance to infections. Proof for this theory exists in the fact that most of these conditions can be reversed after cessation of tobacco use. ${ }^{14}$ In the present study population a majority of the responders were aware 
that smoking causes bad breath, staining of teeth, change in taste, gum disease and cancer of the oral cavity. However they were not aware the smoking could lead to tooth decay.

It was seen that $76.3 \%$ of the participants were not aware that smoking could cause problems of the reproductive system. However $72 \%$ agreed that smoking during pregnancy could harm the baby. Carbon monoxide and nicotine found in tobacco smoke is known to cause foetal hypoxia and retard growth of the foetus resulting in low birth weight. Passive smoke inhalation during infancy causes retardation of the growth of the child leading to decreased height and head circumference. ${ }^{15}$

Recognition by the International Classification of Diseases of 'tobacco dependence' as a disease has made it imperative that the medical personnel take serious note of this disease. Although all health professionals have a role to play in the reduction of tobacco use, the role of dentists is unique as they interact with the patients more frequently. Therefore, dentists have multiple occasions where they can educate tobacco users and help them in quitting of the habit. This makes the dental office an ideal setting for education, motivation, assessment, screening and followup. ${ }^{16}$ In the present survey population, all of the participants were in agreement that smoking was addictive. $71.4 \%$ said that they expected their dentists to explain about the ill-effects of smoking. $75.6 \%$ of the male responders and $61.5 \%$ of the female responders showed an inclination towards quitting and $82.1 \%$ said that dentists should assist them during their quitting phase.

Tobacco cessation practices are aimed at primary; secondary and tertiary levels. ${ }^{17}$ Primary prevention aims to limit the individual's exposure to causative agents and reduces their vulnerability to such agents. ${ }^{18}$ this could be done at policy level, community level and level of the individual. Government of India introduced the Cigarette Act in 1975 which necessitates the inclusion of strong and rotatory warnings on tobacco products in regional languages, ban of advertisement of tobacco products in mass media, ban on smoking in public places, tobacco awareness programs in institutions and mass media and efforts to persuade farmers to cultivate alternative crops. ${ }^{17}$ All of the responders in the present survey agreed to having observed the warning on the labels of tobacco products and $93 \%$ were aware of the ban on smoking in public places. Secondary prevention mainly aims at early diagnosis and prompt treatment to prevent further progression. Tertiary care aims predominantly at surgically removing the tumour mass along with chemotherapy and radiotherapy followed by palliative care and post-operative follow-up to reduce morbidity. ${ }^{19}$

Cessation of smoking can be achieved either pharmacologically or through behaviour management. Pharmacological methods of cessation are frequently obtained as over the counter (OTC) medications. These are recommended for general population and high risk groups including adolescents, pregnant and breast feeding women and those suffering from cardiovascular disease. ${ }^{20}$ Pharmacological approach includes two general strategies: nicotine replacement therapy (NRT) and bupropion therapy. NRT includes the use of lozenges, sublingual tablets, inhalers, nasal spray, transdermal patch and nicotine gum. ${ }^{14,20}$ The rate of cessation is seen to improve by $70 \%$ when measured at the end of the year. ${ }^{20}$

Nicotine gums are available as a 2-4 mg preparation and transdermal patch which is worn for 24 hours provides a daily dose of 7-22 mg of nicotine which is comparable to the trough levels in the plasma of a heavy smoker. To increase compliance, a combination of gum with patch or nasal spray along with a prescription of anti-depressants or anxiolytics may be given. The combination of bupropion with NRT has the highest success in smoking cessation. ${ }^{20,21,22}$ However, adverse effects such as gastrointestinal disturbances and hiccoughs with gums; nasal irritation and irritation of the throat with nasal spray; burning sensation in the mouth, sore throat, hiccoughs, oral ulcers and cough with sublingual tablets should be kept in mind while prescribing NRT. NRT is also known to cause chest pain, heart palpitations, rise in blood pressure and heart rate and constriction of coronary vessels. However, since 
cardiovascular effects of pharmacologic therapy will probably be less when compared to that caused due to smoking, patients should be encouraged to continue with their cessation efforts. ${ }^{20,23,24}$

In the present study, $52.2 \%$ of the male responders stated the reason for their habit was to relax or destress. While $17.5 \%$ of men smoked in order to improve their focus, $7.6 \%$ said they smoked to satisfy an urge. However women denied these as being their reasons to continue their habit. $80.7 \%$ of women stated that they smoked to socialize. Similarly Sarason et al reported that among adolescents, females started the habit due to social pressure while both males and females continued the habit for the pleasure derived from smoking. ${ }^{25} \mathrm{~A}$ study conducted by Khurshid et al stated that the main reason for smoking among teenagers was to cope with stress, to be socially acceptable

\section{References}

1. Henningfield JE, Stolerman IP, Miczek KA. Nicotine psychopharmacology research: advancing science, public health, and global policy. Psychopharmacology 2006; 184:263-5.

2. Blot WJ, M CLaughlin JK, Winn DM, Austin DF, Greenberg RS, PrestonMartin S, Bernstein L, Shoenberg JB, Stemhagen A, Fraumeni JF. Smoking and drinking in relation to oral and pharyngeal cancer. Cancer Res 1988; 48:3282-7.

3. WHO. Tobacco or health: a global status report. Geneva: World Health Organization, 1997.

4. Yanbaeva DG, Dentener MA, Creutzberg EC, Wesseling G, Wouters EF. Systemic effects of smoking. Chest 2007; 131:1557-66.

5. Arnson Y, Shoenfeld Y, Amital H. Effects of tobacco smoke on immunity, inflammation and autoimmunity. Journal of Autoimmunity 2010; 34:J258-J265.

6. SaririR,Varasteh A, Erfani A, Rezaei A, Heidari Z. Inhibition of salivary peroxidase by cigarette smoke. Health 2010; 2:347-51.

7. Sansone GC, Raute LJ, Fong GT, Pednekar MS, Quah ACK, M BansalTravers M, Gupta PC, Sinha DN. Smokers in India: Findings from the tobacco control policy (tcp) India pilot survey. Int J Environ Res Public Health 2012; 9:564-78.

8. Rani M, S Bonu, P Jha, S N Nguyen, LJamjoum. Tobacco use in India: Prevalence and predictors of smoking and chewing in a national cross sectional household survey. Tob control 2003; 12:e4.

9. Strachan DP, Cook DG. Health effects of passive smoking. Parental smoking and childhood asthma: longitudinal and case-control studies. Thorax 1998; 53:204-12.

10. Vellappally S, Fiala Z, Smejkalova J, Jacob V, Somanathan R. Smoking related systemic and oral diseases. ActaM edica 2007; 50:161-6.

11. Bjartveit K, Tverdal A. Health consequences of smoking 1-4 cigarettes per day. Tob Control 2005; 14:315-320.

12. Celermajer DS, Sorensen KE, Georgakopoulos D, Bull C, Thomas O, Robinson J, Deanfield JE. Cigarette smoking is associated with doserelated and potentially reversible impairment of endotheliumdependent dilation in healthy young adults. Circulation 1993; 88:2149-55.

13. Lagrue G, Branellec A, Lebargy F. Toxicology of tobacco. Rev Prat 1993; 43:1203-7.

14. Sham ASK, Cheung LK, Jin LJ, Corbet EF. The effects of tobacco use on and since they liked the taste and feel. ${ }^{26}$ To the best of our knowledge this study is the first of its kind to evaluate the reasons behind smoking among adults in India. This data will help in structuring tobacco cessation protocol to better suit this demographic and thereby improve the rates of quitting and compliance to cessation efforts.

\section{Conclusion}

Patient education, oral screening and preventive measures have always been integral parts of dental healthcare setups which makes it easy to administer tobacco counselling. Such clinical settings are increasingly gaining popularity for tobacco cessation counselling as patients are found to be more receptive to advice. This study sheds light on the level of awareness among current tobacco users and the areas of deficiency in patient education which should be addressed by the clinicians.

oral health. Honh Kong M ed J 2003; 9:271-7.

15. Cornelius MD, Day NL. The Effects of Tobacco Use During and After Pregnancy on Exposed Children: Relevance of Findings for Alcohol Research. Alcohol Res Health 2000; 24(4):242-9.

16. Patil PU, Vivek S, Chandrasekhar T, Parimi N, Praveen BH, Lingaraj S. Patient receptivity to tobacco cessation counselling and services in a dental teaching institute: A patient review. Journal of International Oral Health 2015; 7:1-4.

17. Sridharan G. Epidemiology, control and prevention of tobacco induced oral mucosal lesions in India. Indian J Cancer 2014; 51:80-5.

18. Dinshaw KA, Shastri SS, Patil SS. Cancer control programme in India: Challenges for the new millenium. Health administrator 2004;XVII:103.

19. Rogers NS. Quality of life for head and neck cancer patients- has treatment planning altered? Oral Oncol 2009; 45:435-9.

20. Mills E, Wu P, Lockhart I, Wilson K, Ebbert JO. Adverse events associated with nicotine replacement therapy (NRT) for smoking cessation. A systematic review and meta-analysis of one hundred and twenty studies involving 177,390 individuals. Tobacco Induced Diseases 2010; 8:8

21. Fiore M C, Kenford SL, Jorenby DE, Wetter DW, Smith SS, Baker TB. Two studies of the clinical effectiveness of the nicotine patch with different counselling treatments. Chest 1994; 105:524- 33.

22. Jorenby $D E$, Leischow $S$, Nides $M A$, et al. A controlled trial of sustained-release bupropion, a nicotine patch, or both for smoking cessation. N EnglJ M ed 1999; 340:685-91.

23. Wallstrom M, Sand L, Nilsson F, Hirsch JM. The long-term effect of nicotine on the oral mucosa. Addiction 1999; 94:417-23.

24. Joseph AM, Norman SM, Ferry LH, Rochazka AVP, Westman EC, Steele BG, Sherman SE, Cleveland M, Antonuccio DO, Hartman N, M cGovern PG. The safety of transdermal nicotine as an aid to smoking cessation in patients with cardiac disease. New EJ M ed 1996; 24:1792-7.

25. Sarason IG, M ankowski ES, Peterson AV,Dinh KT. Adolescents' reasons for smoking. Journal of School Health 1992; 62:185- 90.

26. Khurshid F. Causes of smoking habit among the teenagers. Interdisciplinary Journal of Contemporary Research In Business 2012; 3:848-55. 